\title{
PARTNER EVALUATION AND SELECTION IN VIRTUAL ENTERPRISES USING A PROFILE THEORY BASED APPROACH
}

\author{
Stamatios Tsakopoulos, Albert Bokma, Valentina Plekhanova \\ University of Sunderland, Sunderland SR6 ODD, UK \\ s_tsakopoulos@hotmail.com \\ albert.bokma@sunderland.ac.uk \\ valentina.plekhanova@sunderland.ac.uk
}

\begin{abstract}
Virtual enterprises have been widely promoted as a new business paradigm that will allow participants from several organisations to jointly respond to business opportunities that would have been beyond the reach of them individually. Several reference models have been proposed that address issues such as the co-ordination and management of virtual enterprises, but are missing a crucial element, namely the prior evaluation of the potential for success, based on the resources brought together by the participating organisations. What is required is a systematic approach, which will provide for selection and evaluation of participants in order to form viable virtual enterprises. This paper discusses the importance of capability and compatibility factors of the candidate companies that wish to join a virtual enterprise. An approach has been developed and is presented here together with the results of an evaluation.
\end{abstract}

\section{INTRODUCTION}

Over the past few years the concept of the virtual enterprise has become a buzzword. This involves the collaboration of different companies to take advantage of a business opportunity and for each business opportunity a different set of expertise is required. From the perspective of a candidate company the tactic therefore is to assess the resources and expertise required versus that which is currently available and to identify missing expertise and resources and look for potential business partners to be able to respond to and exploit the business opportunity. Consequently, if the required expertise and resources cannot be found within the company, the company has to seek partners with the required expertise and form the so-called virtual enterprise in order to exploit the business opportunity at hand. In the absence of suitable information and communication technology this is difficult to achieve in practice but technological advances of the Internet and the World Wide Web have served to make such business models a real possibility. The current developments in virtual enterprise research focus mainly on co-ordination and management and which is undoubtedly needed to support the efficient operation of this business model, however research in areas such as partner evaluation and selection during the configuration phase of a virtual enterprise is limited but needed to get viable virtual enterprises off the ground in the first place and reduce risk for 
the parties involved. The configuration of virtual enterprises implies that, for a given business opportunity, the requirements need to be assessed to determine what expertise and resources are needed for delivering successfully against it. This requires a selection process of who will participate in the virtual enterprise and what resources will have to be made available. The importance of partner selection in virtual enterprise has been recognised in the literature (Gunasekaran, 2001) as well as the need to further investigate how partner selection will be conducted and how it can be supported (Van Wijk et. al, 1998; Carmarinha-Matos et. al., 1999) but concrete evaluation methods are still missing. In this paper we present such an approach, that takes into account knowledge and skills of the proposed resources and to evaluate the overall capability and compatibility against the requirements, and which has been evaluated in a use case from the construction sector.

\section{EVALUATION METHODS REPORTED IN THE LITERATURE}

An approach for evaluating companies, which intend to enter a Virtual Industry Cluster, has been proposed by (Caballero et al., 2000), where he identifies three different types of evaluation: a) Evaluation of Enterprise Components (Product, Process and Capabilities) b) Identification of Core Competencies and c) Evaluation of Infrastructure Elements. The model discusses the need of product evaluation using the standard industry classification as a filter to reduce the number of companies involved in the pool that make or provide relevant products/services with respect to the aim of the pool. Furthermore he suggests the use of benchmarking techniques (European Network for Advanced Performance Systems ENAPS, Performance Benchmarking System PBS) to evaluate the business processes and ends with the evaluation of capabilities of human resources within the company to perform parts of the processes.

The method proposed by Caballero, is specifically designed for virtual industry clusters where opportunities for forming Virtual Enterprises will occur. The model takes into consideration the type of business opportunities the Virtual Industry Cluster is moving towards and then evaluates the participants on the basis of the product that they make, their business processes and their capabilities as a company to perform these processes. Although the approach would appear to be adequate for evaluating companies to enter into the Virtual Industry Cluster, it does not consider the compatibility of the capabilities of the participant organisations for a given business opportunity and provide the appropriate evaluation of these factors nor is it necessarily flexible enough to deal with ad hoc virtual enterprise formation where the candidate organizations are not already part of the same cluster.

Another approach to automate the process of partner selection is introduced by (Jawonski et al., 1999). The main aim of this approach is to reduce the need for human decision making in the partner selection process. The method for partner selection that he proposes considers two main entities a) Service and b) Provider named as part of a Service-based model. Service is any kind of activity that is required from the Virtual Enterprise. Provider refers to the company that will be able to deliver this service. Thus a virtual enterprise aims to deliver a service or product to its customer by using the services offered by its members. The partner selection 
process first identifies the service that the Virtual Enterprise should deliver to its customers. If an entity can be found to deliver this service solely, the partner selection stops. Usually though, the need for support services will appear that contribute parts of the service that needs to be delivered to the customer. These auxiliary services, as named by Jawonski, can be found by iterating this search process to other companies. When all services have been addressed then the partner search stops.

The above method provides facilities for searching for potential participants rather than evaluating participants. However, the meaning of the entity Service is not very clear with respect to what its detailed characteristics are. The approach proposed however lacks a detailed treatment of the quality and amount of the resources needed to deliver against a given business opportunity and the provision of analysis at that level. In terms of quantitative risk analysis techniques, a mathematical model to propose a method for partner selection can be found in (Ip et al., 2001). The main factors the method considers in order to provide support to the partner selection process are: a) cost, b) due date c) precedence of sub-project d) risk. In detail his scenario says that in practice the Virtual Enterprise evaluates the cost of each sub-project (he means the contribution of each partner) and then the partners that can accept the cost constraints will respond to the bid, then evaluation based on factors like risk and due date will decide the participants of the Virtual Enterprise.

Another area where resource considerations are prevalent is project management. The noticeable difference to Virtual enterprises however is, that in this case the methods tend to operate not at a company level but at an employee level and hence do not necessarily adequately support an evaluation at an enterprise level. The area of project management is addressing the capability evaluation by the use of skill matrices (Wysocki, 2000). This technique is a heuristic approach that refers to two sets of matrices. The first one is called the needs inventory which basically presents the activities in association with the necessary skills for each activity and the second one present the staff in association with their skills. Bringing together these two matrices a third one is produced, called Staff Assignments and associations between staff and activities, can be obtained. The matrix approach, considers as critical factors the skills and compatibility of these skills with respect to what the task or activity requires. The method does not consider the depth of knowledge of this particular skill that is required which indicates that it does not consider capability in its totality and that also affects the compatibility factor too.

In summary, while it is true to say that while a number of propositions have been made to better address the issues of partner selection and matching against the requirements of the profile of a proposed virtual enterprise especially where that virtual enterprise can assemble in an ad hoc fashion rather than out of an existing cluster, the evaluation techniques still need further refinement in order to be able to express more precisely the requirements of a virtual enterprise in terms of the resources that are needed and evaluating alternative configurations of potential participants in order to satisfy the requirements at a qualitative and quantitative level. An approach to this end is presented in the following sections and the results of evaluation with a realistic scenario and with the collaboration of several respondents from the construction sector is reported subsequently. 


\section{CAPABILITY AND COMPATIBILITY FACTORS AS MAIN CRITERIA FOR PARTNER EVALUATION}

In the literature on virtual enterprises the phrase identification of core competencies has dominated the field of partner identification and selection. (Teerhag, 1996) defines this as the profitable usage of skills aiming at an objective oriented performing of a task and that suggests that core competence is the synthesis or configuration of the knowledge and skills available in an enterprise and directed at a specific goal. (Hamel et. al, 1994) identifies three different layers of abstraction. Meta-core competence: That which makes the company recognized, as a result of the product(s) or service(s) a company delivers. Core-competence: This is the aggregation of constituent skills towards the meta-core competence. Constituent skills: These are the main capabilities of the company that may compose the company's core-competence. The constituent skills are the knowledge and skills available in the company that are partially or as a whole utilized as part of the core competence of the company. These are important since the evaluation of the partners needs to consider the knowledge and skills making up the core competence. The core competencies, represent the aggregation of skills available to be employed in developing a particular product or service. Finally, the meta-core competence, is the result of the core competencies. Considering only the meta-core competence is not enough for evaluating a candidate for the virtual enterprise, because the virtual enterprise will probably not use a product off-the-shelf. Instead the virtual enterprise is a team effort that makes use of tangible skills and knowledge of the participant companies and is focused on the requirements of the business opportunity it addresses itself to.

The importance of this aspect in virtual enterprises is recognised by (Jagers et. al., 1998) who argues that the primary characteristic of a virtual organisation is the pooling of the participant's core competencies or core processes/activities. This implies that the virtual enterprise has to make strategic use of expertise, but it does not focus on the fact that this expertise needs to be compatible with what the virtual enterprise requires. (Eversheim, et. al., 1998) by contrast say that the successful development of virtual enterprises relies on finding suitable core competencies in Virtual Industry Clusters and the right fit and integration of these competencies to meet the customer requirements by the virtual enterprise. Furthermore, (Kluber, 1998) extends this viewpoint by explaining what core competence will be within the context of virtual enterprises and stresses that as a generic strategy the virtual enterprise should focus on its objectives and the required core competencies for the virtual enterprise. This includes human and technological competencies as well as the ability to co-operate. Additionally, he goes one step further arguing that the focus on core competencies and the determination of an adequate degree of collective strategy should be covered in the configuration phase.

Underlying the above points of view is the recognition that the core competencies or better the knowledge and skills of the participants, play a key role for the success and failure of the virtual enterprise; also that the availability of the required resources and the quality of those actually employed significantly affects the success or failure of the virtual enterprise in question. The knowledge and skills of an organisation are a quality characteristic that defines the potential of that organization. It is part of the processes of any organization and which we refer to as 
capability. Additionally, the mutual suitability of the partners' capabilities needs to be considered. When a partner is considered for joining a virtual enterprise, the capabilities of the partner have to be considered per se but also with respect to the requirements of the virtual enterprise as a whole and the other partners involved. The required capabilities of a virtual enterprise versus the actual capabilities of a given partner introduces another factor, which we refer to as compatibility.

\section{A PROFILE BASED APPROACH FOR MEASURING CAPABILITY AND COMPATIBILITY FACTORS}

As pointed out earlier, capability and compatibility of the candidate companies are critical factors for the viability of the virtual enterprise. The profile theory, originally proposed by (Plekhanova, 1999), provides techniques to evaluate them. Profile theory has been mainly applied to measuring and evaluating of the capability and compatibility of human resources in project management.

\subsection{Profile Definition}

A profile as presented in (Plekhanova, 1999) is a set of factors that describe object internal properties such as: $\varepsilon_{i}$ the time characteristic of the factor and signifies the length of experience; $v_{i}$ the property of the factor which denotes the level or complexity of the factor; $w_{i}$ the weight of the factor and depicts the importance or priority of the factor. Thus, a profile $b$ is the set of factors $b_{1}, b_{2}, \ldots, b_{n}$ such that $b=$ $\left\{b_{i}, i=\overline{1, n}\right\}$ where $b_{i}=\left(l_{i}, e_{i}\right) ; l_{i}=$ the label or name of the factor; $n=$ number of factors; $e_{i}=$ a 3-tuple of the factor $e_{i}=\left\langle\varepsilon_{i}, v_{i}, w_{i}\right\rangle$. These properties can be introduced by the following table for an example set of factors relating to the requirements of geological, geotechnical and foundation design expertise of a candidate project (the level of complexity is defined here as junior $=1$, intermediate $=2$ and senior $=3$ ):

\begin{tabular}{|c|c|c|c|c|}
\hline \multicolumn{5}{|c|}{ Profile b } \\
\hline $\begin{array}{l}\text { Number of } \\
\text { factor }\end{array}$ & $\begin{array}{l}\text { Label/name of } \\
\text { factor }\end{array}$ & $\begin{array}{l}\text { Length of experience } \\
\text { in years }\end{array}$ & $\begin{array}{l}\text { Level of } \\
\text { complexity }\end{array}$ & $\begin{array}{l}\text { Importance of } \\
\text { factor }\end{array}$ \\
\hline 1 & Foundation Design & 10 & 3 & $4 / 10$ \\
\hline 2 & $\begin{array}{l}\text { Geotechnical } \\
\text { Analysis }\end{array}$ & 12 & 3 & $3 / 10$ \\
\hline 3 & Geological Analysis & 9 & 2 & $3 / 10$ \\
\hline
\end{tabular}

Table 1 - Set of Factors for a Sample Project

Based on the definitions of the knowledge and skills factor three different types of measurements are provided, which are the basis for comparing human resources, namely the measurement of capability profile, compatibility weight and compatibility length and which are explained below.

\subsection{Capability Profile}

The available factor, capability $V_{i}$ with respect to required factor capability is 
defined as follows (Plekhanova, 1999):

$$
V\left(b_{i}\right)=\pi_{w_{i}}\left(\frac{\varepsilon_{i}}{\varepsilon_{i}^{0}}\right)\left(\frac{v_{i}}{v_{i}^{0}}\right)^{2}
$$

where in application to knowledge and skill factors: $\varepsilon_{i} / \mathcal{\varepsilon}_{i}^{(0)}$ is the available time divided by the required time and which signifies the available time of experience in the specific skills by the required time of experience; $v_{i} / v_{0}{ }^{(0)}$ is the available level divided by the required level of experience of the skills (e.g. junior, senior that can be put in a scale $1,2, \ldots, n) ; w_{i}$ is the priority factor and where the sum of all $w_{i}$ for a given profile is always equals to 1 . Consequently, if there is a set with a number of knowledge and skills $n$ and assuming that the knowledge and skills from the set have equal priority then the priority factor would be $l / n$. Thus, the overall capability profile is determined by the sum of $V\left(b_{i}\right)$ by the following formula:

$$
V(b)=\pi \sum_{i=1}^{n} w_{i}\left(\frac{\varepsilon_{i}}{\varepsilon_{0}^{0}}\right)\left(\frac{v_{i}}{v_{0}^{0}}\right)^{2}
$$

The capability profile is applied to the definition of the individual skills of human resources with relation to their knowledge of these skills that can be defined by the years and level of their experience.

\subsection{Compatibility Length and Compatibility Weight}

Compatibility length can be described by the following formula (Plekhanova, 1999):

$$
\rho(b)=\frac{m}{n}
$$

where $m$ is the number of available factors that satisfy the required ones and $n$ is the number of required factors. Compatibility length refers to the length of the skills and knowledge that an individual has with respect to the requirements for skill and knowledge of certain activities.

Compatibility weight is defined as the factor that represents the compatibility of the available profile capability with the required profile capability (Plekhanova, 1999):

$$
w(b)=\prod_{i=1}^{n}\left(\frac{\varepsilon_{i}}{\varepsilon_{0}^{0}}\right)\left(\frac{v_{i}}{v_{0}^{0}}\right)^{2}
$$

\section{ADAPTABILITY OF THE PROFILE THEORY FOR EVALUATING PARTNERS}

The profile theory is used for measurement of the knowledge and skills capability and compatibility factors on an individual human resource level and therefore evaluations can be carried out as to who is the most appropriate resource for a given tasks or activity (Plekhanova, 1999). In the case of virtual enterprises, the requirement is to find organisations that can match one or more roles that have been identified, as well as the quantity of human resources that required for these roles. 
Profile theory, as it stands, provides a way to compare and select specific individuals with respect to the required capabilities and compatibilities of the project. For the selection of an organisation as a participant in a virtual enterprise the evaluation of capabilities and compatibilities of a number of employees that can fulfill the requirements of the virtual enterprise is required. We propose the construction of a process, which incorporates the application of profile theory in order to evaluate the requirements of virtual enterprise as a whole. To facilitate such a process, it is necessary: to establish the interactions as to how the information necessary for applying profile theory will be collected; to identify when and how the profile theory will be applied; to identify how the factor quantity of resources (human) per role can be incorporated in the model; to identify whether infrastructure support for the application of profile theory can be provided in order to automate and speed up the process of evaluation of participants.

\section{THE PROPOSED PROFILE THEORY BASED APPROACH}

We suggest performing knowledge and skills capability and compatibility analysis through the use of Profile Theory in order to evaluate candidate companies that wish to be members of the virtual enterprise via an evaluation of their human resources. In order to make knowledge and skills capability and compatibility analysis applicable for that type of evaluation there is a need for introducing a number of elements, which assist on using appropriately the profile theory. Required Knowledge and Skills Profile refers to the required skills/knowledge, experience, level, priority factors and quantity required for a specific role. The difference between the required presented at this point and the required profile presented in the profile theory is the factor quantity. When a virtual enterprise seeks for partners it may require a company, which has employees with the skill set required in the quantity of more than one (i.e. 3 Geotechnical Engineers). Thus, the factor quantity has to be taken into consideration. Company's Knowledge and Skills Master Profiles The company's knowledge and skills master profile includes all the knowledge and skills capability profiles of the people that aimed to be used in the project. In this case there is not only the profile of the capability factors of one only individual but it can be more than one depending on the quantity is required for the particular role. Knowledge and Skills Capability \& Compatibility Analysis (Application of Profile Theory) is the core part of this process. It is indeed the tool assists on identifying the appropriate partners. Thus, during capability and compatibility analysis the company's master profile is compared with the required profile to produce some results. Based on these results the selection takes place. Knowledge and Skills Filters are the factors like capability profile, compatibility length, compatibility weight and quantity. Depending on the values of these factors a number of companies are suggested as the appropriate companies for a given role. In detail, if the capability profile of the employees of a company is greater or equal than the required, the compatibility length of the employees is greater or equal to 1 , the compatibility weight greater or equal to 1 and the quantity is greater or equal than the required quantity, then this company is suggested as a qualified partner for a given role based on factors like knowledge and skills. It must be noticed at this stage that filters can be adjusted for cases of realizing and viewing the differences in capabilities and compatibilities of different companies. 
The process depicted in Figure 1 starts by breaking down the project to a list of activities/tasks (see A1.1). Then the knowledge and skills required for the completion of each activity needs to be estimated (A1.2). Additionally roles are defined for those that need to undertake these activities (A1.3 \& A1.4). Then the quantity of human resources per role identified is estimated (A1.5). All this information is used later to construct a profile (A1.6), which can be distributed to the candidate companies (A1.7). Therefore each required profile consists of a role name; a set of activities assigned to this role; a set of required knowledge and skills per activity; the quantity of human resources required for each role. So the required knowledge and skills profile is defined and contains the skills/knowledge, experience, level of experience, priority factors, and quantity for each role. Subsequently, the required knowledge and skills profiles need to be distributed to the candidates that want to participate in the virtual enterprise in order for them to create their company knowledge and skills master profiles.

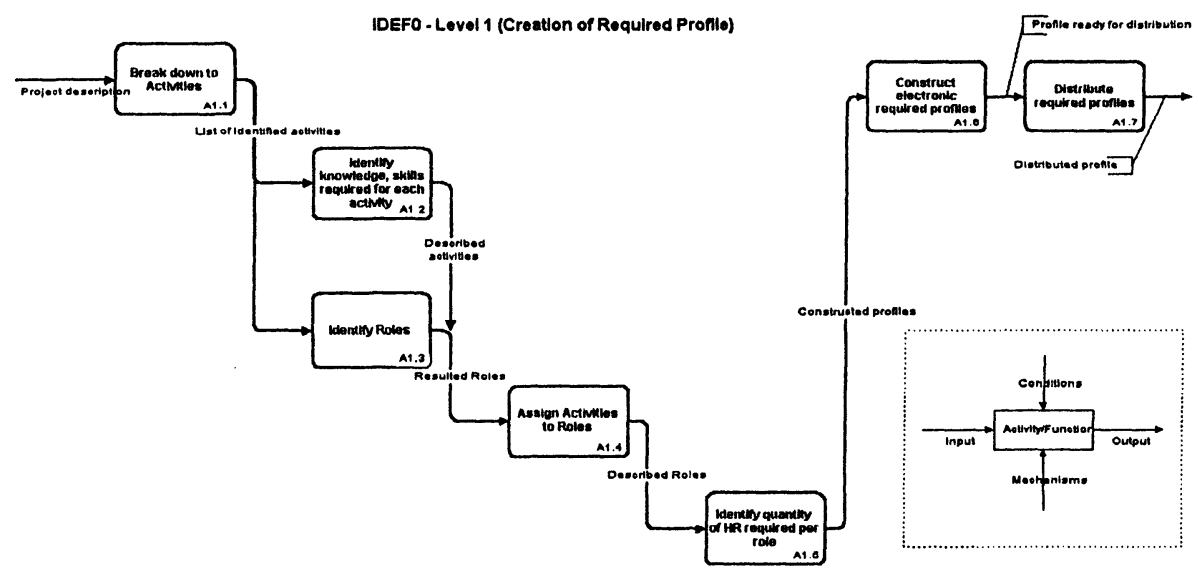

Figure 1 - The process of constructing profiles

This profile involves the actual capabilities of the company with respect to the roles they propose to undertake. In more detail one company master profile consists of the role or roles that the company wishes to undertake in the virtual enterprise; the human resources associated to roles; the set of knowledge and skills of the human resources associated with a role. Afterwards, the companies' master profiles must be collected/received, validated and placed to Companies Knowledge and Skills Master Profiles Repository. The validation process of the companies' master profiles involves the checking of whether it contains the information required. Furthermore, when all the companies' knowledge and skills master profiles are in the repository, capability and compatibility analysis takes place for identifying which companies are the most capable to undertake certain roles. Each company's master profile is examined individually and the factors like capability profile, compatibility length and compatibility weight are measured (A1.1). Also at this stage measurement for the capability profile, compatibility length and compatibility weight takes place for the required profile in order to find out what is required for each role and then being able to compare it with the values from the actual companies master profiles. The 
values of the required profile are used for the filtering of the results of this analysis (A1.2). Afterwards, depending on the results of this analysis, the most capable companies will be filtered with respect to the roles have been assigned and therefore the project's master profile can be created, which includes the companies and their associated roles for this project (A1.3).

\section{CURRENT PRACTICE AND EVALUATION OF THE PROPOSED METHOD}

Before providing details on the evaluation of the proposed method with a use case from the construction sector it is appropriate to briefly reflect on current practice in the industry. Construction on the whole is an interesting example as this sector has a long-standing tradition of operating the virtual enterprise business model long before that business model received the virtual enterprise label. Construction projects of significant size have for a long time been based on a sub-contracting basis where a large company has bid for a project and subsequently involved a considerable number of sub-contractors to deliver parts of the overall project. At the same time there is a marked absence in the sector of use of formal techniques for managing the resource analysis associated with such projects and instead heuristic methods are used and which are expected of a competent project manager. Thus skilled project managers have to decide which companies to involve in any particular project and to satisfy themselves that the risks associated with defaulting sub-contractors is minimised in order not to jeopardise the overall project. Project managers in this position tend to work by previous experience of working with sub-contractors as well as references and portfolios in order to decide whether to involve a particular sub-contractor or not. While the method evidently works in a majority of cases, when the project becomes large and complex and the involvement of individual subcontractors become large and complex problems can arise as the project manager may no longer be able to rely on rough estimations and rules of thumb to provide a reasonably accurate estimation of the resources required and the ability of subcontractors to deliver. Public authorities, by contrast, who are on the contracting end of a substantial number of large public works contracts have for some time required evidence of the main contractor to deliver on a given contract. In this case a more formal presentation of the availability of suitable resources to match the project programme of work therefore needs to be supplied by the main contractor. This matches the work programme in terms of a bill of resources much the same way as there is a bill of materials to be used in the process of construction. This contains detail about: 1) Project methodology to specify the project management methods and tools to be used, including strategies of how to overcome technical difficulties and summary of equipment resources to be used. 2) Recruitment to provide detail of the current organisation and its structure as well as the personnel including their technical/scientific background and teams to be formed including CVs. 3) Experience with similar projects providing a portfolio of past projects. 4) Current workload of the company to assess the availability of the resources required.

While it is recognised that the approach taken by public authorities is useful and informative there are two problems associated with its wider use also across sub- 
contractors: Its application is resource intensive and usually there are neither the resources available to implement it and it is in practice unfeasible to procure all the details from prospective sub-contractors as a basis of evaluation. Finally, while this set of information does provide detail there is no method available to analyse it formally rather requiring the user to perform his own analysis on this basis. The proposed profile based approach has been evaluated with a group of three construction companies from Greece, namely Archimedes SA, Ekter SA and Anastilotiki SA. The study used a real test case from a previous project from one of these companies concerning the construction of an underwater tunnel where a subcontractor was required to perform a geological study in preparation of the actual construction. The test case was given to a number of respondents to perform selection from a number of candidates based on their heuristic approach for selection. The following table shows the summative results for the analysis carried out by these three companies: As can be seen from table 2, the results were within certain ranges differing usually one or two points there still is a considerable amount of variation due to the subjective nature of the evaluation. By contrast the alternative, formal approaches are able to generate much more objective results and the test case data was fed into a matrix analysis, which, for the geotechnical engineer alone yielded the following results:

\begin{tabular}{||l|c|c|c|}
\hline COMPANY & ARCHIMEDES S.A & EKTER S.A & $\begin{array}{c}\text { ANASTILOTIKI } \\
\text { S.A }\end{array}$ \\
\hline Geomihaniki S.A & 5 & 4 & 4 \\
\hline Geniki Meleton Ltd. Istria & 1 & 1 & 1 \\
\hline Edafomihaniki S.A & 3 & 5 & 4 \\
\hline Edafos Ltd. & 2 & 2 & 3 \\
\hline OTM S.A & 4 & 4 & 5 \\
\hline Geognosi S.A & 1 & 1 & 1 \\
\hline Pangea Ltd. & 4 & 3 & 2 \\
\hline Asproudas \& Sinergates & 1 & 1 & 1 \\
\hline Mallios S.A & 1 & 1 & 1 \\
\hline Geoplan Ltd. & 1 & 1 & 1 \\
\hline
\end{tabular}

Table 2 Comparison of Evaluation

While the matrix approach is thorough in terms of focusing on individual skills that are required and that are present or absent from a proposed subcontractor, they nevertheless do not explicitly represent nor evaluate the depth of skills required nor the amount of skilled personnel at that level to complete the task; they merely show the existence of a set of skills in a given organisation in matrix form. The profilebased approach, by contrast, provides an analysis at this level. For a more detailed description of the evaluation and results the reader is referred to (Tsakopoulos 2003). In conclusion, there are some interesting observations that can be made about the experiment and the results. The heuristic approach evidently exhibits variations in the results due to the subjective nature of the heuristics involved and at the same time a full analysis as used by public authorities is not feasible - a result which was confirmed by results from a survey of the respondents from these three 
companies. The matrix approach has definite benefits in making the exact profile of skills needed versus that present in candidate companies explicit but lacks a more detailed treatment vis-à-vis depth of experience and amount of resources of that type. It is therefore not possible to get results from this method at that level. The profile based approach allows to assess the skill-set available versus that required at the level required that takes into account depth of skill and amount of resources. Respondents from the companies concerned were also asked to comment on the results of the profile-based approach and about the feasibility of its implementation. $70 \%$ of respondents stated that records of profiles from companies on past projects were kept and also $70 \%$ of respondents thought that the profile-based analysis would be beneficial to them.

\section{CONCLUSIONS}

In this paper we have stressed the need for developing a solution to support the partner evaluation and selection in order to form virtual enterprises. The importance of knowledge and skills of organisations have been highlighted as key factors for evaluating candidate companies. Furthermore, the use of Profile Theory as a tool for evaluating candidates via an evaluation of their human resources has been presented. Finally, an operational approach to the evaluation using profile theory has been presented. Some of the most important characteristics of the profile-based approach can be summarised as follows: it evaluates human resources by taking into consideration organisational changes; it ensures that the appropriate data is collected for a full evaluation; it makes explicit when and how capability and compatibility analysis will take place; it introduces a new factor (quantity of human resources per role); it automates the process of partner evaluation and speeds up the process of partner evaluation. The results from the evaluation have been very positive and have demonstrated the feasibility of the application of this approach in real scenarios. In addition the majority of respondents when presented with the method and the results responded very positively to the practical use of the method and its usefulness in practical application in the process of sub-contractor evaluation. While some very thorough benchmarking techniques can be applied as suggested for a cluster approach to virtual enterprise formations the approach presented here provides a strong alternative for scenarios where no prior clustering is feasible or desirable. In addition the proposed approach uses a pragmatic and economic approach where the available resources are compared against the requirements to assess the suitability of prospective participants in a virtual enterprise.

\section{REFERENCES}

1. Caballero D., Molina A., Bauernhansl T., A methodology to evaluate enterprises to become members of Virtual Industry Clusters, Second IFIP Conference on Infrastructures for Virtual Organisations: Managing Cooperation in Virtual Organisations and Electronic Business Towards Smart Organisations, December 4-6, 2000, Florianapolis, Brazil.

2. Carmarinha-Matos L.M., Afsarmanesh H., Further Developments in Virtual Enterprises, $1^{\text {st }}$ IFIP Conference on Infrastructures for Virtual Enterprises: Networking Industrial Enterprises, October 27-28, 1999, Porto, Portugal. 
3. Eversheim W., Bauernhansl T., Bremer C., Molina A., Schuth S., Walz M., Configuration of Virtual Enterprises based on a framework for global Virtual Business, Proceedings of the VoNetWorkshop-in organisational Virtualness, 1998.

4. Gunasekaran A., Next generation computer-integrated manufacturing strategies and techniques, int $j$ computer integrated manufacturing, 2001 vol. 14 no 2, 000-000.

5. Hamel G., Heene A.A Competence Based Competition, John Wiley \& Sons, 1994

6. Ip W.H., Min Huang, Yung K.L., Wang D., Genetic algorithm solution for a risk-based partner selection problem in a virtual enterprise, Computers \& Operations Research, Elsevier, http://www.elsevier.com, 2001.

7. Jagers H.P.M, Steenbakkers G.C.A, Co-ordination and use of ICT in Virtual Organisations, EGOS Conference, 1998.

8. Jawonski T., Yonghe L., Boqhing H., Automating Partner Selection For a Virtual Organisation, IFIP Conference on Infrastructures for Virtual Enterprises: Networking Industrial Enterprises, October 27-28, 1999, Porto, Portugal.

9. Kluber R., A Framework for Virtual Organising, Proceedings of the VoNet- Workshop in organisational Virtualness, 1998.

10. Plekhanova V., Capability and Compatibility measurement in software process improvement, $2^{\text {nd }}$ European Software Measurement Conference-FESMA'99, October 4-8, 1999, Amsterdam, Netherlands.

11. Teerhag O., Model for transforming identifying and optimising core processes (MOTION), 1996.

12. Tsakopoulos S., A Capability-Bas3e Approach for Evaluating the Viability of Virtual Enterprises, MPhil thesis, February 2003, University of Sunderland, UK

13. Wijk J.V., Geurts D., Bultje R., 7 steps to virtuality: understanding the Virtual Organisation processes before designing ICT-support, OOPSLA, Vancouver, 1998.

14. Wysocki, R Beck, D B Crane, Effective Project Management, R K John Wiley \& Sons, ISBN: 0471-36028-7, 2000. 